\author{
A. UNIWERSAŁ *,\#, M. WROBEL*, S. WRONSKI**, I. KALEMBA-REC*, M. WRONSKI**, K. WIERZBANOWSKI**, A. BACZMANSKI**, \\ B. BACROIX***
}

\title{
THE EFFECT OF LOW DEFORMATION ASYMMETRIC ROLLING ON MICROSTRUCTURE AND TEXTURE OF THE POLYCRYSTALLINE COPPER
}

\begin{abstract}
In the most recent years the asymmetric rolling (AR) attracts attention of researchers and technologists. This process can improve some technological parameters (e.g. modification of rolling torque and load, power requirements, etc.) as well as provide the possibility of grain refinement in a relatively inexpensive way. Most of the reports concerning microstructural changes produced by $A R$ refer to high deformations imposed in highly asymmetric conditions. However, such rolling conditions are difficult to control, so there are no prospects to their quick industrial implementation. The present paper refers to relatively low deformation and low asymmetry rate, that is much more interesting for the industry. It was shown that bending of the rolled band (important disadvantage of the $A R$ technology) can be controlled by adjusting of the amount of deformation and asymmetry. It was also shown that ca. $30 \%$ reduction in thickness during cold rolling, together with a relatively low asymmetry, reduces significantly the grain size and produces a more fragmented microstructure inside grains of the polycrystalline copper comparing to the symmetric rolling $(S R)$. The material hardness after AR is higher than after the $S R$. Moreover, the crystallographic texture asymmetry, expressed by its rotation around the transverse direction, is observed in the $A R$ material.
\end{abstract}

Keywords: Asymmetric rolling, polycrystalline copper, microstructure refinement, strip curvature

\section{Introduction}

The symmetric rolling $(S R)$ is commonly applied for the manufacturing of the flat products like plates and sheets or strips. In this process the symmetry plane is situated in the rolled band mid-thickness. However, only recently an asymmetric rolling process attracted the attention of researchers and technologists. It is believed that such a process, referred to as the asymmetric rolling $(A R)$, may improve some technological parameters (e.g., modification of rolling torque and load, power requirements, etc.) as well as may provide a relatively inexpensive way of grain refinement [1-4]. This is possible due to an increased shear deformation and its distribution across the rolled metal thickness. The $A R$ can be realized by different peripheral velocities of rolls, different roll diameters or by applying a different degree of lubrication on both rolled surfaces. The asymmetry ratio, $A$, may be defined as a ratio of the roll diameters or their angular velocities or also as a ratio of friction coefficients between opposed rolls and the rolled material. The available literature on the $A R$ often refers to steels [3-9], aluminum [1, 10-13] and titanium alloys [2, 1415]. The recent study on polycrystalline copper concerns large asymmetries applied to the highly deformed material after the $S R$ process [16].

It is believed that industrial application of the $A R$ should be relatively simple. However, it involves some important practical issues, especially for highly asymmetric processes $(A>1.5)$. The rolled strip curvature, bending up or down, horizontal forces detrimental for roll necks and potentially harmful vibrations can be particularly dangerous. That is why the practical implementation of the $A R$ on existing modern mills, accurately designed for working in lines, is difficult. These difficulties have been overcome in a specially designed constructions [17, 18], but even in such cases a low asymmetry processes are usually applied industrially (e.g. [18, 19]). The low asymmetry $A R$ can be easier controlled by only a modest modification of typical rolling mills. However, the attention of technologists is often oriented towards technological parameters [20-26] but the microstructure effects are neglected. Also, the modification of residual stresses induced by an improved processing technology should be considered [27, 28].

The aim of the present paper was to study the $A R$ process realized at small amount of deformation and small rolling asymmetry, applied to the technically pure polycrystalline copper. The influence of the $A R$ on the rolled strip curvature and microstructure parameters was examined.

\section{Experimental procedure}

Samples of commercial pure copper, of the size of $5 \times 25 \times 100 \mathrm{~mm}^{3}$, were annealed during $1.5 \mathrm{~h}$ at $450^{\circ} \mathrm{C}$ and

\footnotetext{
* AGH UNIVERSITY OF SCIENCE AND TECHNOLOGY, FACULTY OF METALS ENGINEERING AND INDUSTRIAL COMPUTER SCIENCE, AL. MICKIEWICZA 30, 30-059 KRAKÓW, POLAND

** AGH UNIVERSITY OF SCIENCE AND TECHNOLOGY, FACULTY OF PHYSICS AND APPLIED COMPUTER SCIENCE, AL. MICKIEWICZA 30, 30-059 KRAKÓW, POLAND

*** LSPM-CNRS UNIVERSITÉ PARIS 13, 99 AV. J.B. CLEMENT, 93430 VILLETANEUSE, FRANCE

\# Correspondence address: auniwers@agh.edu.pl
} 
then symmetrically and asymmetrically cold rolled on the laboratory mill with the reductions in thickness of $17 \%, 25 \%$ and $32 \%$ (always realized in a single pass). Two identical rolls of $180 \mathrm{~mm}$ diameter were powered by independent motors, revolving with different angular velocities: $\omega_{1}$ and $\omega_{2}$. The anisotropy ratio of the process was defined as:

$$
A=\frac{\omega_{1}}{\omega_{2}}
$$

The angular velocity of the lower roll, $\omega_{1}$, was constant and equal to $10 \mathrm{rpm}$, while the velocity of the upper roll was adjusted in such a way that the A value was equal to $1.0(S R)$ or comprised in the range 1.10-1.50 $(A R)$. Immediately after rolling, the surface of each sample, that was in touch with the upper roll, was marked. Since some of the rolled samples were bent up or down, their curvature was measured. The curvature was defined as a height of an $\operatorname{arch}(\Delta H)$ on the standard length of sample equal to $55 \mathrm{~mm}$. A bend in the direction of the upper roll was taken as positive and the bend in the opposite direction - as negative.

Two kinds of samples were chosen for further examination: SR samples, with $A=1.0$, and $A R$ ones, with $A=1.50$. The results presented in this paper deal with material layers from the center of the rolled bar. The hardness was measured on the longitudinal sections of the rolled bars (i.e., on the $R D-N D$ surface) located in the middle of the rolled bar width, where the $R D$ and $N D$ stand for rolling and normal directions, respectively) by the Knoop method, using the Wilson Instruments Tukon 2500 tester. The average hardness, was calculated from at least 35 measurements. These measurements were performed on samples that were electrolytically polished in the same way as the samples used for the Scanning Electron Microscopy (SEM) examination. Polishing was performed in the Struers solution D2 at the voltage of $15 \mathrm{~V}$ and temperature of $10^{\circ} \mathrm{C}$.

The Electron Back-Scatter Diffraction $(E B S D)$ patterns were measured on a Scanning Electron Microscope FEI Nova NanoSEM 450 (the tested area was $c a .1190 \times 1025 \mu \mathrm{m} 2$ and the step size of $0.2 \mu \mathrm{m}$ was used). The EBSD measurements were performed on the longitudinal sections, located in the middle of the rolled bar width and were confined to areas located at mid-thickness of the rolled bar. The TSL OIM Analysis 7 software was used for data analysis and the grain definition based on recommendations of the standard ASTM E2627-13 was applied.

The $\{111\},\{200\},\{220\}$ and $\{311\}$ incomplete pole figures were measured using the parallel beam of $\mathrm{Cu} K \alpha$ X-ray radiation on the Empyrean diffractometer from PANalytical Co. The measurements were performed in the plane parallel to the rolling plane and located in the middle of the rolled bar thickness. Before X-ray measurements, the exposed surfaces were gently polished and etched. The experimental pole figures were used to calculate the orientation distribution function $(O D F)$ [29] from which, in turn, complete pole figures were calculated. LaboTex [30] commercial software was used for this purpose.

\section{Results and discussion}

\subsection{Specimen curvature}

The effect of bending of the rolled strip is shown in Fig. 1. A small increase of the rolling asymmetry, starting from $A=1$, produces a significant flexure of the rolled sample towards the faster upper roll. Such a behavior was typical for three tested reductions in specimen thickness $(17 \%, 25 \%$ and $25 \%$ ). Generally, a decrease of the $\Delta H$ parameter versus $A$ was observed for each deformation. It is apparent from Fig. 1 that the maximum upward deflection (max. value of the $\Delta H$ parameter) appears for $A$ values from the range $1.05-1.25$ for $32 \%$ thickness reduction. In contrast, in the case of lower reductions $(17 \%, 25 \%)$ this maximum appears in the narrow range of $A$ between 1.05 and 1.10. It is also visible that the $\Delta H$ maximum value increases nearly two times when the reduction in thickness altered from $17 \%$ to $32 \%$. Moreover, for each of the examined deformations one can find an asymmetry ratio, $A$, for which the straight band can be obtained: $A \approx 1.10$ for the $17 \%$ and $25 \%$ thickness reductions of and $A \approx 1.30$ for the $32 \%$ reduction. Therefore, the rolled band bending, that constitute an important disadvantage of the $A R$ technology, can be controlled by convenient values of strain and asymmetry.

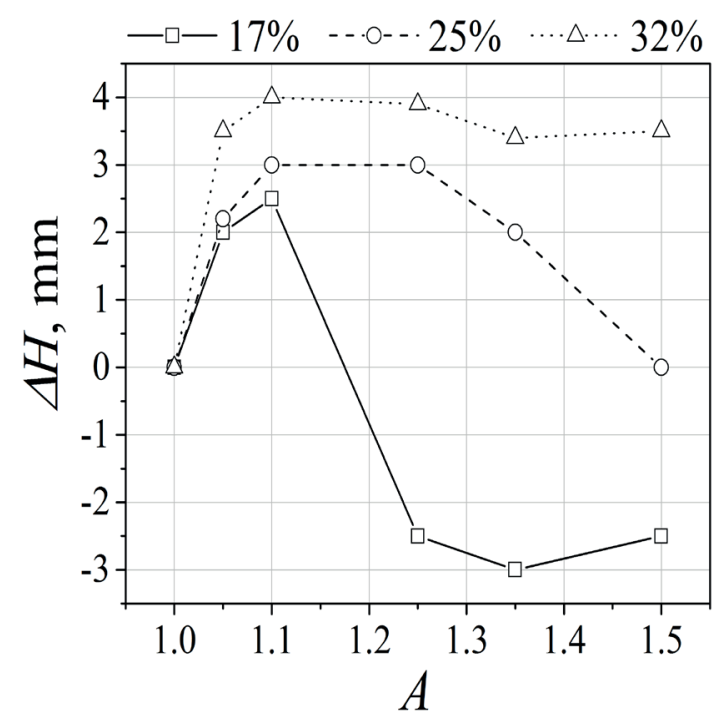

Fig. 1 Effect of rolling deformation and asymmetry $(A)$ on the curvature of the rolled specimen $(\Delta H)$

\subsection{Microhardness}

A significant hardening upon deformation is a typical behavior and it was also found in the examined material. It is worth to note that the higher hardness was typical for the $A R$ specimens than for the $S R$ ones, for each investigated deformation. The average hardness value of the $S R$ and $A R$ samples rolled to $32 \%$ reduction is shown in Fig. 2 . The relative difference in hardness, about $2.7 \%$, is almost independent 
of the amount deformation. This result indicates different plastic strain states in the $S R$ and $A R$ materials deformed to the same reduction. It is an interesting result, because usually hardness is related to the amount of the total deformation but the contribution of the strain state is neglected. The observed difference in hardness is related to changes in microstructure. Therefore, smaller grains and/or higher dislocation density is expected in the $A R$ material. This hypothesis is verified in the next sections of this work.

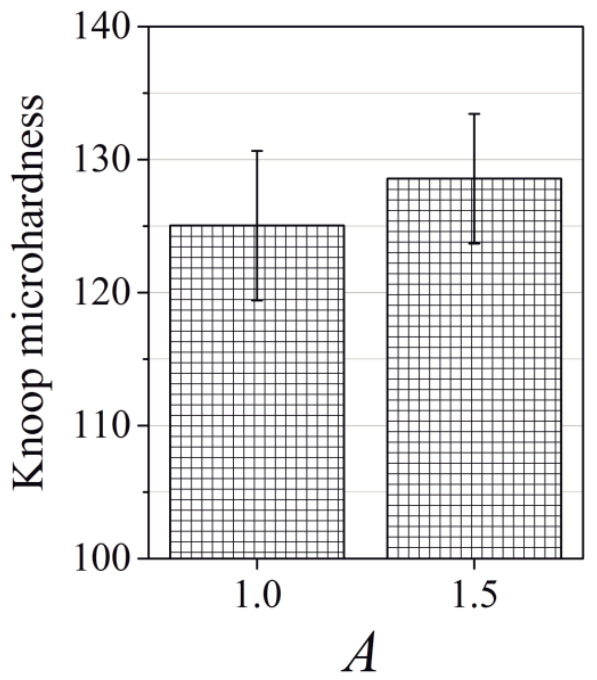

Fig. 2 Hardness of the rolled materials: thickness reduction is equal to $32 \%$

\subsection{Crystallographic textures}

The effect of the $A R$ on the texture development can be clearly shown on pole figures. Such a representation of texture is generally preferred by the industrial community. That is why it was also presented in this work. The complete $\{111\}$ pole figures are shown in Fig. 3. In this figure, the pole positions for selected ideal orientations, characteristic for textures of f.c.c. rolled metals, are also shown, i.e.: $W$ (Cube), $B$ (Brass) and $C$ (Copper) and $G$ (Goss) orientations. The initial material had a relatively weak texture but the presence of the $W, B$ and $C$ components could be observed (Fig. 3a). In contrast, the intensities of $B$ and $C$ components are strongly increased in the rolled samples (Figs $3 b$ and c). In spite of the relatively small amount of deformation ( $32 \%$ reduction in thickness), the typical cold rolling texture of copper-type could be recognized in the deformed samples.

The $\{111\}$ pole figure of the $S R$ sample shows the orthorhombic symmetry despite the fact that no such a sample symmetry was assumed during its calculation. This indicates an accuracy of the $S R$ process (Fig. 3b). The transverse direction $(T D)$ is in this case the two-fold symmetry axis. On the other hand such a symmetry does not exist in the case of the $A R$ material (Fig. 3c). It is apparent that the $A R$ texture is rotated around the $T D$, compared to the $S R$ texture. The rotation angle is about $7^{\circ}-8^{\circ}$. Such a texture rotation can be explained by differences of the stress state during rolling resulting from an increased value of the shear stress in the $A R$ material. These effects can be explained using the crystal deformation model (e.g. [31]). The detailed analysis of this effect is beyond the scope of this paper and will be published elsewhere.

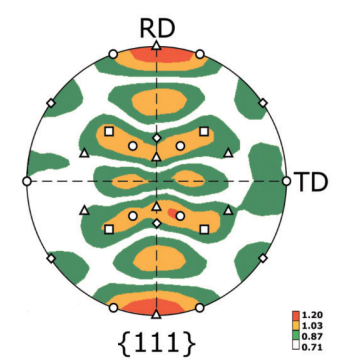

b)

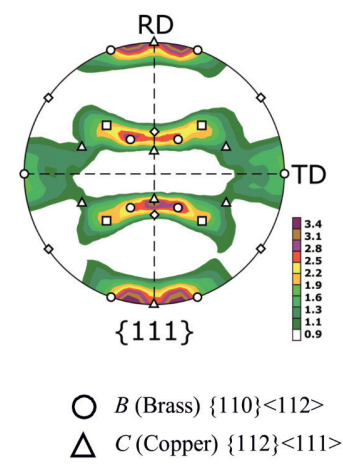

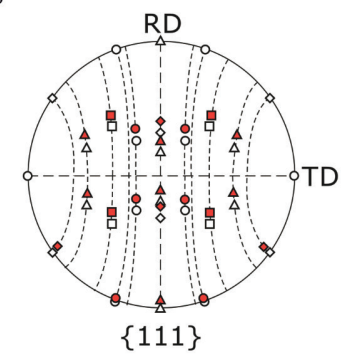

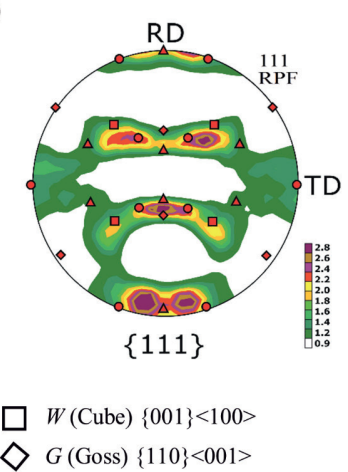

Fig. $3\{111\}$ pole figures measured in centre layers of the initial material (a) and of the $S R$ (b) and $A R$ (c) samples rolled to the thickness reduction of $32 \%$. Position of texture components for $S R$ materials (empty symbols) and $A R$ materials (field symbols) are marked (d)

\subsection{Microstructure parameters determined from EBSD measurements}

The EBSD investigation of the copper samples rolled symmetrically $(A=1)$ and asymmetrically $(A=1.5)$ to $32 \%$ reduction in thickness shows the effects of $A R$ despite a relatively small amount of deformation.

Firstly, the average area of grains surrounded by a low angle boundaries is about $13 \%$ smaller for the $A R$ than for the $S R$ material (Fig. 4a). It should be noted that in this case grains were defined basing on boundary misorientation exceeding 50 . However, for grain definition based on boundary misorientations higher than 150 - the effect of $A R$ is within an experimental error. This result shows that AR modifies more strongly the average area of grains surrounded by the low angle boundaries than that surrounded by the high angle boundaries. It was also found that the average aspect ratio differs between two rolling modes: it is about $2 \%$ higher in the case of the AR material (Fig.4b).

Secondly, for the $A R$ material the grain average misorientation $(G A M)$ and the kernel average misorientation $(K A M)$ are significantly higher than for SR material (Figs 5 and $6)$. These two parameters characterize local misorientations and can be related to the energy stored in the dislocation structures, which depends on the dislocation density and configuration (cf. [32]). The GAM provides the average misorientation between each pair of neighboring measurement points inside grain. Hence, it is sensitive to the dislocation structure and their density. The GAM distribution for the $A R$ material is generally shifted towards higher values (Fig. 5a). The average 
$G A M$ is about $3 \%$ higher for the $A R$ material (Fig. $5 b$ ). On the other hand, $K A M$ is calculated as the average misorientation between measurement points and their neighbors. However, misorientations exceeding some tolerance value (i.e., maximum misorientation - $M M$ ) are excluded. Two values of $M M$ were examined: $M M=5^{\circ}$ and $M M=15^{\circ}$ (Fig. $6 \mathrm{~b}$ ). The first value is appropriate for revealing misorientation inside sub-grains and is related to dislocations forming sub-boundaries, while the second one detects also dislocations forming low angle grain boundaries. It is visible in Fig.6b that both distributions (for $M M=5^{\circ}$ and for $M M=15^{\circ}$ ) are shifted towards higher $K A M$ values for the $A R$ material: they are higher by about $8 \%$ and $14 \%$ for $M M=5^{\circ}$ and $M M=15^{\circ}$, respectively. This shows a significant increase of the strain energy stored inside grain sub-boundaries and low angle grain boundaries due to the $A R$ process. The difference in $K A M$ and $G A M$ values also shows that grain boundary statistics are different in the two examined rolling processes. a)

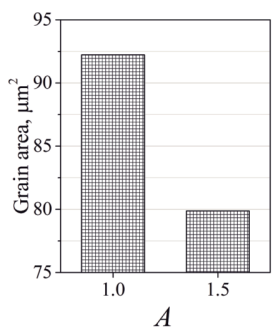

b)

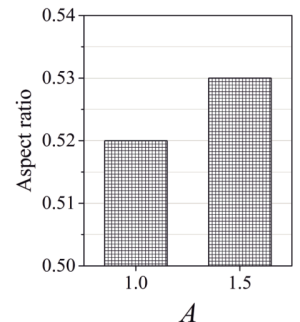

Fig. 4 Average grain size area (assuming grain boundary misorientation exceeding $5^{\circ}$ ) (a) and average aspect ratio (b) for symmetrically $(A=1.0)$ and asymmetrically $(A=1.5)$ rolled samples; thickness reduction is equal to $32 \%$
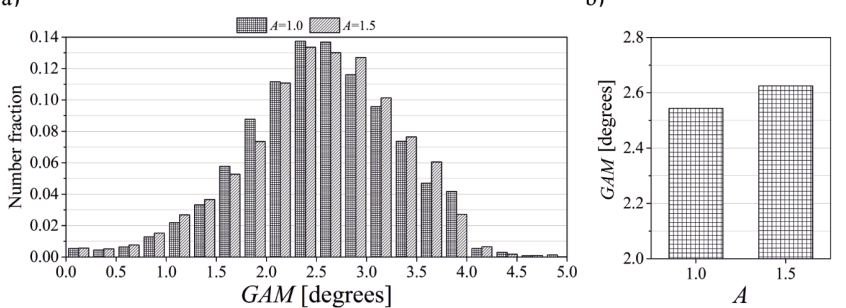

Fig. 5 Grain average misorientation $(G A M)$ distribution (a) and its mean values for symmetrically $(A=1.0)$ and asymmerically $(A=1.5)$ rolled samples (b); thickness reduction is equal to $32 \%$ a)

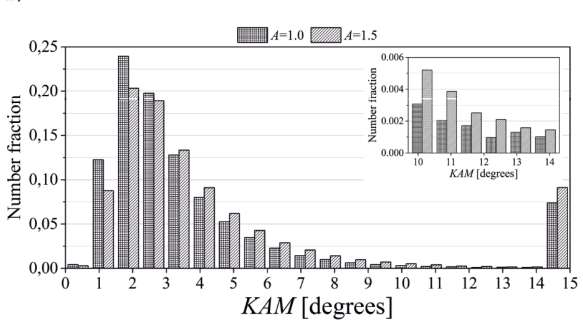

b)

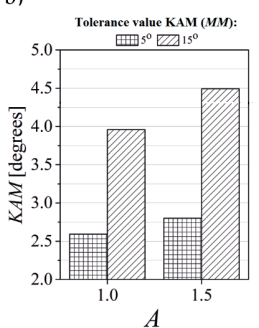

Fig. 6 Kernal average misorientation $(K A M)$ distribution (a) and its average values for $5^{\circ}$ and 150 maximum misorientations $(M M)$ for symmetrically $(A=1.0)$ and asymmerically $(A=1.5)$ rolled samples (b); thickness reduction is equal to $32 \%$

\section{Conclusions}

1. The bending of the material rolled asymmetrically can be controlled by an appropriate selection of the applied strain and the rolling asymmetry ratio $A$.

2. Hardness for the asymmetrically rolled material $(\mathrm{A}=1.5)$ is about $5 \%$ higher than for the material rolled symmetrically.

3. The crystallographic texture of the material rolled symmetrically shows the orthorhombic symmetry. In the middle of the sample thickness the texture of the asymmetrically rolled material $(A=1.5)$ is rotated around the transverse direction (TD) with respect to the texture of the symmetrically rolled material. The rotation angle is about $7-8^{\circ}$.

4. The reduction in thickness as low as $32 \%$ is sufficient to show the effect of asymmetric rolling $(A=1.5)$ on the grain refinement. The average grain area (assuming grain boundary misorientations between $5^{\circ}$ and $15^{\circ}$ ) is about $13 \%$ lower in the asymmetrically rolled material comparing with the symmetrical rolling one. What is more, the asymmetrically rolled material is locally more fragmented, which is expressed by higher values of the grain average misorientation (GAM) and the kernel average misorientation (KAM) parameters.

\section{Acknowledgements}

This work was supported by the National Science Centre on the basis of decisions DEC-2013/09/N/ST8/04164 and DEC-2013/11/B/ST3/03787. Valuable help of M.Sc. Eng. M. Wacławik (AGH) is appreciated.

\section{REFERENCES}

[1] J. Jiang, Y. Ding, F. Zuo, A. Shan, Scripta Mater. 60, 905-908 (2009).

[2] M. Wroński, K. Wierzbanowski, M. Wróbel, S. Wroński, B. Bacroix, Met. Mater. Int. 21, 805-814 (2015).

[3] M. Salimi, M. Kadkhodai, J. Mater. Process. Tech. 150, $215-$ 222 (2004).

[4] H. Takechi, Recent progress in high strength steels for automobile in Japan, HSLA Steels 2005, Proc. of the 5th International Conference on HSLA Steels, Sanya, Chine, Sanya, Hainan, China,. Peking: The Chinese Society for Metals., p. 58 (2005).

[5] M. Wroński, K. Wierzbanowski, S. Wroński, B. Bacroix, Ch. Thierry, M. Wróbel, J. Cent. South Univ. 20, 1443-1455 (2013).

[6] S. Wroński, K. Wierzbanowski, B. Bacroix, M. Wróbel, M. Wroński, Mat. Sci. Forum 638-642, 2811-2816 (2010).

[7] S. Wroński, K. Wierzbanowski, B. Bacroix, M. Wróbel, E. Rauch, F. Montheillet, M. Wroński, Arch. Metall. Mater. 54, 89-102 (2009).

[8] A. Kawałek, J. Mater. Process. Tech. 155-156, 2033-2038 (2004). 
[9] J. Liu, R. Kawalla, T. Nonfer. Metal Soc. 22, 388-391 (2012).

[10] S. Wroński, B. Ghilianu, T. Chauveau , B. Bacroix, Mater. Charact., 62, 22-34 (2011).

[11] M. Wroński, K. Wierzbanowski, S. Wroński, B. Bacroix, M. Wróbel, A. Uniwersał, Proc. 17th International Conference on Textures of Materials (ICOTOM 17), IOP Conf. Series: Mater. Sci. \& Eng. 82, 012074 (2015).

[12] S. Dutta, M. S. Kaiser, J. Mech. Eng. 44, 94-99 (2014).

[13] S-B. Kang, B-K. Min, H.-W. Kim, D. S. Wilkinson, J. Kang, Metall. Mater. Trans. A 36, 3141-3149 (2005).

[14] M. Wroński, K. Wierzbanowski, A. Baczmańsku, S. Wroński, B. Bacroix, M. Wróbel, A. Lodini, Adv. Mater. Res. 996, 688693 (2014).

[15] M. Wroński, K. Wierzbanowski, L. Pytlik, B. Bacroix, M. Wróbel, A. Baczmański, A. Lodini, Mat. Sci. Forum 777, 1-6 (2014).

[16] W. Polkowski P. Jóźwik M. Polański Z. Bojar, Mat. Sci. Eng. A 564, 289-297 (2013)

[17] T.R. Kurahashi, K. Hakomori, I. Chikushi, T. Morimoto, J. Yanagimoto, S. Takaoka, La Revue de Métallurgie 102, 271285 (2005).

[18] T. Morimoto, F. Yoshida, I. Chikushi, J. Yanagimoto, ISIJ Int. 47, 1475-1484 (2007).

[19] G. Muralidharan, T.R. Muth, Y. Wang, E. Specht, T.R. Watkins, B. Radhakrishnan, G.B. Sarma, S. Angew, Oak Ridge National
Laboratory project ID\#LM058 for US Department of Energy (2011-2013).

[20] E.A. Maksimov, Metallurgist 54, 753-757 (2011).

[21] P.P. Gudur, M.A. Salunkhe, U.S. Dixit, Int. J. Mech. Sci. 50, 315-327 (2008)

[22] Y. Pang, Y. Hu, Q. Sun, Ch. Liu, Adv. Mater. Res. 97-101, 597-600 (2010).

[23] F. Fartherna, M. Salimi, IJEST 3, 147-163 (2011).

[24] S.A.A. Akbari Mousavi, S.M. Ebrahimi, R. Madoliat, J. Mater. Process. Tech. 187-188, 725-729 (2007).

[25] J-S. Lu, O-K. Harrer, W. Schwenzfeier, F. D. Fisher, ISIJ Int. 42, 49-61 (2000)

[26] A. Kawałek, AMME 23, 63-66 (2007).

[27] A. Baczmański, K. Wierzbanowski, J. Tarasiuk, M. Ceretti, A. Lodini, La Revue de Métallurgie 94, 1467-1474 (1997).

[28] A. Baczmański, A. Tidu, P. Lipinski, M. Humbert, K. Wierzbanowski, Mater. Sci. Forum 524-525, 235-240 (2006).

[29] H.J. Bunge, Texture Analysis in Material Science: mathematical methods, London, Butterworths, Boston 1982.

[30] LaboTex, Software for Texture Analysis, Labosoft s.c., Kraków, Poland (2014).

[31] K. Wierzbanowski, A. Baczmanski, P. Lipinski and A. Lodini, Arch. Metall. Mater. 52, 77-86 (2007).

[32] A. Baczmański, N. Hfaiedh, M. François, K. Wierzbanowski, Mater. Sci. Eng. A 501, 153-165 (2009). 
